\title{
Police Officers' Ability in Recognizing Relevant Mental Health Conditions
}

\author{
Linus Wittmann ${ }^{1 *}$, Gunter Groen ${ }^{2}$, Petra Hampel ${ }^{1}$, Ronja Petersen ${ }^{3}$ and \\ Astrid Jörns-Presentati ${ }^{2}$ \\ ${ }^{1}$ Department of Health Psychology and Health Education, Europa-Universität Flensburg, Flensburg, Germany, ${ }^{2}$ Department \\ of Social Work, University of Applied Sciences Hamburg, Hamburg, Germany, ${ }^{3}$ Hamburg Police Academy, Hamburg, \\ Germany
}

The recognition of certain mental health conditions is important as this requires police officers to communicate and behave in an adjusted manner with affected individuals. The objective of the present study was to test police officers' knowledge about mental health symptoms as a component of their mental health literacy (MHL) and to examine if police officers' perceived knowledge corresponds with their actual knowledge. A questionnaire was used to assess for $\mathrm{MHL}$ representing mental health conditions which occur frequently

OPEN ACCESS

Edited by: Craig Bennell, Carleton University, Canada

Reviewed by: Jennifer Lavoie, Wilfrid Laurier University, Canada

Adam Vaughan Texas State University, United States

${ }^{*}$ Correspondence: Linus Wittmann linus.wittmann@uni-flensburg.de

Specialty section:

This article was submitted to Educational Psychology, a section of the journal Frontiers in Psychology

Received: 18 June 2021 Accepted: 16 August 2021 Published: 17 September 2021

Citation: Wittmann L, Groen G, Hampel P, Petersen $R$ and Jörns-Presentati A (2021) Police Officers' Ability in Recognizing Relevant Mental Health Conditions.

Front. Psychol. 12:727341. doi: 10.3389/fpsyg.2021.727341 in police requests (schizophrenia, bipolar disorder, depression, post-traumatic stress disorders, and emotionally unstable personality disorder). Furthermore, the questionnaire assessed the frequency of police requests, the officers' perceived knowledge regarding mental disorders and their sense of feeling sufficiently trained to deal with these kinds of requests. Eighty-two police officers participated in the study. Police officers' actual knowledge about mental health conditions did not correspond with their perceived knowledge. Participants revealed a moderately high level of overall knowledge which differed with regard to symptoms of each of the five mental health conditions. The mental status of a paranoid schizophrenia was best identified by the police officers and the majority correctly allocated the symptoms. Post-traumatic stress disorders and manic episodes were only identified by a minority of police offers. Police training geared to prepare for requests involving individuals with mental disorders should expand this limited knowledge transfer and focus on a broader variety of mental health conditions that police officers frequently encounter in requests.

Keywords: individuals with mental disorders, training, mental health conditions, mental health literacy, police

\section{INTRODUCTION}

There is a large body of research examining interactions between police forces and individuals with a mental health condition (Vigours and Quy, 2017). Previous research examined the frequency (Livingston, 2016), circumstances (Charette et al., 2014), and the subjective experience of affected individuals (Livingston et al., 2014b; Soares and Pinto da Costa, 2019) as well as involved police officers in these interactions (Wittmann et al., 2021c). Additionally, there are studies suggesting that police officers regularly encounter individuals diagnosed with schizophrenia, bipolar disorder, depression, post-traumatic stress disorders (PTSD) or emotionally unstable personality disorders (EUPD; Resnick et al., 2000; Kesic et al., 2013; Jones and Thomas, 2019; 
O'Neal, 2019). The crisis intervention team training (CIT) program proposes that police officers require knowledge about different kinds of mental health conditions in order to correctly detect them in real life situations (Watson and Fulambarker, 2012; CIT International, 2019). It is thought that the ability to recognize and identify certain mental health conditions enables police officers to adjust their communication strategies and behavior with a focus on procedural justice, empathy and patience to prevent the risk of escalating violence and traumatic experiences (Desmarais et al., 2014; Livingston et al., 2014a; Wittmann et al., 2021b). Knowledge about and recognition of mental health conditions is one component of the mental health literacy (MHL) concept. MHL was first described by Jorm et al. (1997) and builds upon the concept of health literacy (Nutbeam, 2000; World Health Organization, 2013). Components of MHL include (a) the ability to recognize specific disorders or psychological distress; (b) knowledge and beliefs about risk factors and causes; (c) knowledge and beliefs about self-help interventions; (d) knowledge and beliefs about available professional help; (e) attitudes which facilitate recognition and help-seeking; and (f) knowledge of how to seek mental health information (Jorm, 2000).

In their regular practice, German police officers are not expected to be able to identify the wide range of symptoms indicating potential mental health symptoms, but they need to be able to recognize certain mental health conditions. However, there is evidence that police officers only identify mental health problems in $50 \%$ of the encounters they have with individuals with mental health issues (McKinnon and Grubin, 2013). To this date, there is a paucity of research examining whether German police officers are capable of correctly identifying individuals suffering from poor mental health. The aim of the present study was therefore to test German police officers' knowledge about mental health symptoms and draw conclusions about the extent to which they are mental health literate. In addition, we tested if police officers' perceived knowledge corresponded with their actual knowledge.

\section{MATERIALS AND METHODS}

\section{Materials}

Two of the authors, a clinical psychologist and a police officer, constructed the questionnaire to assess for MHL based on the criteria of the International Classification of Diseases and related Health Problems 10 (ICD-10; WHO, 2015). We chose five mental health disorders which occur frequently in police requests: schizophrenia, bipolar disorder, depression, PTSD, and EUPD (Resnick et al., 2000; Kesic et al., 2013; Jones and Thomas, 2019; O'Neal, 2019). The questionnaire contained the description of 17 symptoms using clinical terminology (e.g., paranoid delusions) which participants had to assign to one of five different mental health conditions. We used the terminology of the ICD-10 to label symptoms and mental health disorders. To meet the requirements of a practical oriented approach certain symptoms were selected which are (1) characteristic for the respective diagnosis and (2) salient in the communication or the interaction with an individual. Furthermore, the questionnaire inquired about age, gender, and years of service. The frequency of police requests involving individuals with mental disorders was assessed on a five-point Likert scale from several times a day to never before. Police officers were also asked to evaluate their perceived knowledge regarding mental disorders and sense of feeling sufficiently trained to deal with these kinds of requests on a five-point Likert scale $(1=$ very poor to $5=$ very good). To assess the affective component of these interactions, participants were asked a single choice question measuring if they felt predominantly safe, tensed, uneasy or overwhelmed in requests involving individuals experiencing a mental health condition.

\section{Procedure}

The stratified data collection was performed over two weeks in June 2020. Participating frontline police officers were recruited in a large German city. In order to achieve a representative sample of the city, five police departments located in the center and in the western, eastern, southern, and northern districts were chosen. Pervious research showed that police interactions with individuals with mental illnesses are not equally allocated in neighborhoods (Krishan et al., 2014). Therefore, we deemed this approach necessary as different police departments were located in neighborhoods with potentially differing frequencies in police request involving mental disorders. A paper-pencil survey was used as the most practical approach to collect data in the field. The questionnaires were distributed to the selected police departments by a police officer student and handed to the post office boxes of all frontline police officers of the respective police department. Additionally, the superintendents of each unit were personally informed about the study. Based on preliminary considerations of the manpower of each department it was deemed sufficient to provide each department with $N=40$ questionnaires resulting in a potential sample of $N=200$. Additionally, participants were provided with a letter informing about the study and an informed consent form. Participants were able to contact a researcher for any questions regarding the study. Questionnaires and informed consent forms were collected separately in two different sealed boxes over a period of two weeks. This period was chosen in order to increase the response rate in case some police officers would be on vacation or attend training. The sealed boxes were only opened by the researchers to maintain anonymity and confidentiality. The study was reviewed by the respective police academy. This included the involvement of the staff council. In addition, the research is in accordance with the Declaration of Helsinki.

\section{RESULTS}

\section{Participants}

A total of $N=82$ (response rate $=41 \%$ ) police officers participated (33 female, 40.2\%) in the study. The age ranged most frequent from 26 to 35 years $(n=26,32 \%)$ and most police officers $(n=24,29 \%)$ had spent less than 6years in service. Most participants $(n=51,62.2 \%)$ experienced police requests with 
individuals with mental disorders several times per month. The majority $(n=52 ; 63.4 \%)$ estimated their knowledge in the category as moderate (see Table 1 ). The majority of participants ( $n=47 ; 57.3 \%)$ reported they had felt tense during interactions with individuals with mental disorders, about a quarter $(24.4 \%)$ of the participants felt safe, 14 (17.1\%) participants felt uncomfortable, and one (1.2\%) participant felt overwhelmed.

\section{Overall Mental Health Literacy}

In order to test if police officers' actual knowledge corresponded with their perceived knowledge we calculated a knowledge score. This score represents how many symptoms were correctly assigned to one of the five mental health conditions resulting in a possible range from 0 (all incorrect) to 17 (all correct). This score was available for $n=52$ participants due to missing values. Participants average knowledge score was $M=10.94$ $(\mathrm{SD}=2.26)$. A Spearman rank correlation did not show a significant association between the police officers' actual knowledge and subjective knowledge.

\section{Paranoid Schizophrenia}

Fifty-one (62.2\%) participants correctly identified the three key symptoms of paranoid schizophrenia (see Table 2). Paranoid delusions ( $n=67 ; 81.7 \%)$, bizarre delusions $(n=63 ; 76.8 \%)$, and acoustic (auditory) hallucinations $(n=67 ; 81.7 \%)$ were to the same extent correctly identified as symptoms of a paranoid schizophrenia.

\section{Emotionally Unstable Personality Disorder (Borderline Personality Disorder)}

No participant correctly identified all three symptoms of an EUPD. Self-harming behaviors, including suicide gestures, were correctly assigned to EUPD by 54 participants (65.9\%). Outbursts of emotions due to emotional liability were identified by 33 (40.2\%) participants as a symptom of EUPD and seven (8.5\%) participants assigned chronic feelings of emptiness to the disorder.

\section{Post-traumatic Stress Disorder}

Twelve participants (14.6\%) correctly identified all four symptoms of a PTSD. Flash backs were identified by the majority of the police officers $(n=75 ; 91.5 \%)$ as a specific PTSD symptom. Sleeping disturbances $(n=56 ; 68.3 \%)$ and enhanced startle reactions $(n=47 ; 57.3 \%)$ were frequently identified as a PTSD symptom, whereas avoidance behaviors were only identified by one in four participants $(n=20 ; 24.4 \%)$.

\section{Manic Episode}

All symptoms of a manic episodes were only identified by $14(17.1 \%)$ participants. Elevated $\operatorname{mood}(n=48 ; 58.5 \%)$ and inflated self-esteem and grandiose ideas $(n=46,56.1 \%)$ were more frequently perceived as qualifiers for a manic episode than overactivity $(n=37 ; 45.1 \%)$ and reckless behavior $(n=32 ; 39 \%)$.

\section{Depressive Episode}

Thirty-six participants $(n=36 ; 44 \%)$ identified all four symptoms of a depressive episode. Reduction in energy $(n=68 ; 83 \%)$ and lowering of mood 68 (83\%) were identified more frequently as depressive symptoms compared to suicidal thoughts $(n=50$; $61 \%)$ and sleep disturbances $(n=56 ; 68.3 \%$; Table 2$)$.

\section{DISCUSSION}

The aim of the present study was to test police officers' MHL with regard to their knowledge of relevant mental health conditions. Our first finding is that police officers have a moderate knowledge of the symptoms of mental illnesses that they encounter more frequently during police requests. Second, police officers revealed a differentiated knowledge about mental disorders in general: A diagnosis of paranoid schizophrenia was identified most frequently by participants (62\%) and the majority correctly allocated the respective symptoms to the disorder. A depressive episode was the second best identified mental health condition in our sample (44\%). This is in line with research demonstrating that higher rates of individuals diagnosed with schizophrenia or depression compared to other mental disorders come in contact with police (Kesic et al., 2013; McKinnon and Grubin, 2013). Additionally, McKinnon and Grubin (2013) showed that police officers detected symptoms of schizophrenia more commonly compared to other mentals health conditions (e.g., intellectual disabilties). However, one could argue that German police training focuses specifically on schizophrenia and therefore police officers present with a broader knowledge (Wundsam et al., 2007; Wittmann et al., 2021a). In contrast, PTSD (15\%) and manic episodes (17\%) were only identified by a minority of police offers and EUPD by none of the participants. This finding is unexpected, as police encounters with individuals diagnosed with bipolar disorders and EUPD occur relatively often in police requests (Gandhi et al., 2001;

TABLE 1 | Frequency distribution of age, years spent in service, frequency of requests involving individuals with a mental disorder, and perceived knowledge.

\begin{tabular}{|c|c|c|c|c|c|}
\hline Age & $18-25$ & $26-35$ & $36-45$ & $46-55$ & $>56$ \\
\hline$N(\%)$ & 17 (21\%) & 26 (32\%) & 25 (30\%) & $11(13 \%)$ & 3 (4\%) \\
\hline Years spent in service & $<5$ & $6-15$ & $16-25$ & $26-34$ & $>35$ \\
\hline$N(\%)$ & 24 (29\%) & $23(28 \%)$ & $23(28 \%)$ & 7 (9\%) & $5(6 \%)$ \\
\hline Frequency of requests & Multiple times per day & Multiple times per week & Multiple times per month & Less than once in a month & Never before \\
\hline$N(\%)$ & $51(62.2 \%)$ & $23(28 \%)$ & $6(7.3 \%)$ & $2(2.4 \%)$ & - \\
\hline Perceived knowledge & Very good & Good & Moderate & Poor & Very poor \\
\hline$N(\%)$ & $2(2.4 \%)$ & 21 (25.6\%) & 52 (63.4\%) & 7 (8.5\%) & - \\
\hline $\begin{array}{l}\text { Sense of feeling trained } \\
N(\%)\end{array}$ & - & 13 (15.9\%) & 38 (46.3\%) & 27 (32.9\%) & $4(4.9 \%)$ \\
\hline
\end{tabular}


TABLE 2 | Correct and false allocations of the 17 symptoms and five mental health conditions.

\begin{tabular}{|c|c|c|c|}
\hline & Correct, $n(\%)$ & False, $n(\%)$ & Missing, $n(\%)$ \\
\hline Paranoid schizophrenia & $51(62.2 \%)$ & $22(26.8 \%)$ & $9(11 \%)$ \\
\hline Paranoid delusions & $67(81.7 \%)$ & $10(12.2 \%)$ & $5(6.1 \%)$ \\
\hline Bizarre delusions & $63(76.8 \%)$ & 15 (18.3\%) & $4(4.9 \%)$ \\
\hline Acoustic hallucinations & $67(81.7 \%)$ & $8(9.8 \%)$ & $7(8.5 \%)$ \\
\hline Emotionally unstable personality disorder (EUBD) & - & $62(75.6 \%)$ & $20(24.4 \%)$ \\
\hline Liability to outbursts of emotion & $33(40.2 \%)$ & $40(48.8 \%)$ & $9(11 \%)$ \\
\hline Chronic feelings of emptiness & $7(8.5 \%)$ & $68(82.9 \%)$ & $7(8.5 \%)$ \\
\hline Self-destructive behavior, including suicide gestures & $54(65.9 \%)$ & $10(12.2 \%)$ & $18(22 \%)$ \\
\hline Post-traumatic stress disorder (PTSD) & $12(14.6 \%)$ & $51(62.2 \%)$ & $19(23.2 \%)$ \\
\hline Avoidance behavior & $20(24.4 \%)$ & $50(61 \%)$ & $12(14.6 \%)$ \\
\hline Flashbacks & 75 (91.5\%) & $5(6.1 \%)$ & $2(2.4 \%)$ \\
\hline Enhanced startle reactions & $47(57.3 \%)$ & 32 (39\%) & $3(3.7 \%)$ \\
\hline Sleeping disturbances & $56(68.3 \%)$ & $11(13.4 \%)$ & $15(18.3)$ \\
\hline Manic episode & $14(17.1 \%)$ & 49 (59.7\%) & $19(23.2 \%)$ \\
\hline Elevated mood & 48 (58.5\%) & 27 (33\%) & $7(8.5 \%)$ \\
\hline Overactivity & 37 (45.1\%) & $36(43.9)$ & $9(11.0)$ \\
\hline Reckless behavior & 32 (39\%) & $43(52.4)$ & $7(8.5 \%)$ \\
\hline Inflated self-esteem and grandiose ideas & $46(56.1 \%)$ & $30(36.6 \%)$ & $6(7.3 \%)$ \\
\hline Depressive episode & $36(44 \%)$ & $23(28 \%)$ & $23(28 \%)$ \\
\hline Reduction in energy & 68 (83\%) & 7 (8.5\%) & $7(8.5 \%)$ \\
\hline Lowering of mood & $68(83 \%)$ & $3(3.6 \%)$ & $11(13.4 \%)$ \\
\hline Suicidal thoughts & $50(61 \%)$ & $13(15.8)$ & 19 (23.2\%) \\
\hline Sleep disturbances & $56(68.3 \%)$ & $11(13.4 \%)$ & 15 (18.3\%) \\
\hline
\end{tabular}

Kesic et al., 2013). There are two possible explanations for this result. First, the low detection rates may be due to the symptoms we selected that police officers were not familiar with. Second, it is possible that police officers knew the symptoms but were not able to assign these to the corresponding mental health condition. Thus, we suggest that police training that sufficiently prepares police officers for requests involving individuals with mental disorders should focus on expanding police officers' knowledge transfer with a focus on a broader variety of mental health conditions that occur frequently in police requests.

\section{Limitations}

The present study has certain limitations with regard to the measurement and sample used and these should be considered when interpreting the results. First, the questionnaire was constructed in order to test for certain symptoms of selected mental disorders. When describing symptoms we used a clinical terminology offered by the ICD-10 (WHO, 2015). It is possible that participants were not familiar with these terms which could have resulted in unanswered questions or guessing. Future research should examine which terminology police officers use in their daily routines to describe signs of mental symptoms. Second, we only used a limited number of three to four of the symptoms listed in the ICD-10 to represent each mental disorder, which may have limited the validity of the questionnaire. Additionally, some of the symptoms could exist in multiple types of mental illness even if the ICD-10 suggest a clear distinction. The rationale behind this, was our assumption that police officers in the field may also only use selected indicators to screen for mental health conditions instead of conducting comprehensive diagnostics.
Third, the present study did not consider co-occurring mental disorders, however there is a certain amount of individuals that experience multiple diagnoses (Jones and Thomas, 2019). Fourth, the present study comprised a relatively small sample size. We cannot rule out a selection bias, however another recent German study showed comparable sociodemographic characteristics of the police officers sample (Wittmann et al., 2021c). In addition, the sample size is sufficient considering the explorative character of the study. Future research should apply established MHL scales in the field of police work (O'Connor and Casey, 2015) with larger and more representative samples. Further research is needed that examines police officers' abilities to detect if an individual is experiencing active symptoms of a mental health condition in real life encounters as our results are limited to tested knowledge.

\section{CONCLUSION}

The results indicate that German police officers have a moderately high overall but distinct knowledge regarding symptoms of specific mental health conditions. Symptoms of paranoid schizophrenia were correctly identified by the majority of the police officers. Police training that aim to prepare for requests involving individuals with mental disorders (e.g., police use of force training) should also include other mental health conditions known to be relevant for police encounters with individuals with mental health problems, such as EUPD, PTSD, manic episodes and depressive episodes. Future research should examine MHL in police officers with more established measures and in more representative samples. 


\section{DATA AVAILABILITY STATEMENT}

The original contributions presented in the study are included in the article/supplementary material, further inquiries can be directed to the corresponding author.

\section{ETHICS STATEMENT}

Ethical review and approval was not required for the study on human participants in accordance with the local legislation and institutional requirements. The participants provided their written informed consent to participate in this study.

\section{REFERENCES}

Charette, Y., Crocker, A. G., and Billette, I. (2014). Police encounters involving citizens with mental illness: use of resources and outcomes. Psychiatr. Serv. 65, 511-516. doi: 10.1176/appi.ps.201300053

CIT International (2019). Crisis Intervention Team (CIT) programs: a best practice guide for transforming community responses to mental health crises. Retrieved from https://www.citinternational.org/bestpracticeguide (Accessed August 26, 2021).

Desmarais, S. L., Livingston, J. D., Greaves, C. L., Johnson, K. L., and Brink, J. (2014). Police perceptions and contact among people with mental illnesses: comparisons with a general population survey. Psychol. Public Policy Law 20, 431-442. doi: 10.1037/law0000023

Gandhi, N., Tyrer, P., Evans, K., McGee, A., Lamont, A., and Harrison-Read, P. (2001). A randomized controlled trial of community-oriented and hospitaloriented care for discharged psychiatric patients: influence of personality disorder on police contacts. J. Personal. Disord. 15, 94-102. doi: 10.1521/ pedi.15.1.94.18644

Jones, L. B., and Thomas, S. D. M. (2019). A pilot study exploring mental health consumers' experiences with the police. Psychiatry Psychol. Law 26, 235-251. doi: 10.1080/13218719.2018.1504240

Jorm, A. F. (2000). Mental health literacy. Public knowledge and beliefs about mental disorders. Br. J. Psychiatry 177, 396-401. doi: 10.1192/bjp.177.5.396

Jorm, A. F., Korten, A. E., Jacomb, P. A., Christensen, H., Rodgers, B., and Pollitt, P. (1997). "Mental health literacy": a survey of the public's ability to recognise mental disorders and their beliefs about the effectiveness of treatment. Med. J. Aust. 166, 182-186. doi: 10.5694/j.1326-5377.1997.tb140071.x

Kesic, D., Thomas, S. D. M., and Ogloff, J. R. P. (2013). Estimated rates of mental disorders in, and situational characteristics of, incidents of nonfatal use of force by police. Soc. Psychiatry Psychiatr. Epidemiol. 48, 225-232. doi: 10.1007/s00127-012-0543-4

Krishan, S., Bakeman, R., Broussard, B., Cristofaro, S. L., Hankerson-Dyson, D., Husbands, L., et al. (2014). The influence of neighborhood characteristics on police officers' encounters with persons suspected to have a serious mental illness. Int. J. Law Psychiatry 37, 359-369. doi: 10.1016/j. ijlp.2014.02.006

Livingston, J. D. (2016). Contact between police and people with mental disorders: a review of rates. Psychiatr. Serv. 67, 850-857. doi: 10.1176/appi. ps.201500312

Livingston, J. D., Desmarais, S. L., Greaves, C., Parent, R., Verdun-Jones, S., and Brink, J. (2014a). What influences perceptions of procedural justice among people with mental illness regarding their interactions with the police? Community Ment. Health J. 50, 281-287. doi: 10.1007/s10597-012-9571-5

Livingston, J. D., Desmarais, S. L., Verdun-Jones, S., Parent, R., Michalak, E., and Brink, J. (2014b). Perceptions and experiences of people with mental illness regarding their interactions with police. Int. J. Law Psychiatry 37, 334-340. doi: 10.1016/j.ijlp.2014.02.003

McKinnon, I. G., and Grubin, D. (2013). Health screening of people in police custody - evaluation of current police screening procedures in London, UK. Eur. J. Pub. Health 23, 399-405. doi: 10.1093/eurpub/cks027

\section{AUTHOR CONTRIBUTIONS}

LW and RP collected the data and performed the analyses. LW, AJ-P, and GG wrote the original draft. LW, AJ-P, GG, and $\mathrm{PH}$ contributed to the article. All authors contributed to the article and approved the submitted version.

\section{FUNDING}

We acknowledge financial support for Article Publication Charges by Land Schleswig-Holstein within the funding programme Open Access Publikationsfonds.

Nutbeam, D. (2000). Health literacy as a public health goal: a challenge for contemporary health education and communication strategies into the $21 \mathrm{st}$ century. Health Promot. Int. 15, 259-267. doi: 10.1093/heapro/15.3.259

O'Connor, M., and Casey, L. (2015). The mental health literacy scale (MHLS) a new scale-based measure of mental health literacy. Psychiatry Res. 229, 511-516. doi: 10.1016/j.psychres.2015.05.064

O'Neal, E. N. (2019). "Victim is not credible": the influence of rape culture on police perceptions of sexual assault complainants. Justice Q. 36, 127-160. doi: 10.1080/07418825.2017.1406977

Resnick, H. S., Holmes, M. M., Kilpatrick, D. G., Clum, G., Acierno, R., Best, C. L., et al. (2000). Predictors of post-rape medical care in a national sample of women. Am. J. Prev. Med. 19, 214-219. doi: 10.1016/ S0749-3797(00)00226-9

Soares, R., and Pinto da Costa, M. (2019). Experiences and perceptions of police officers concerning their interactions with people with serious mental disorders for compulsory treatment. Front. Psychol. 10:187. doi: 10.3389/ fpsyt.2019.00187

Vigours, C.-A., and Quy, K. (2017). Police responses to people with mental health needs: a systematic map of the literature. Available at: https://whatworks. college.police.uk/Research/Systematic_Review_Series/Pages/default.aspx

Watson, A. C., and Fulambarker, A. J. (2012). The crisis intervention team model of police response to mental health crises: a primer for mental health practitioners. Best Pract. Ment. Health 8:71.

Wittmann, L., Dorner, R., Heuer, I., Bock, T., and Mahlke, C. (2021a). Effectiveness of a trialogic anti-stigma intervention for police forces. Int. J. Law Psychiatry 76:101697. doi: 10.1016/j.ijlp.2021.101697

Wittmann, L., Groen, G., Ogorka, J., and Jörns-Presentati, A. (2021b). "I didn't know what they wanted from me" - the perspective of individuals with mental disorders on police interventions. J. Police Crim. Psychol. 36, 537-542. doi: 10.1007/s11896-021-09449-8

Wittmann, L., Jörns-Presentati, A., and Groen, G. (2021c). How do police officers experience interactions with people with mental illness? J. Police Crim. Psychol. 36, 220-226. doi: 10.1007/s11896-020-09398-8

World Health Organization (2013). Health Literacy. The Solid Facts. Geneva $(\mathrm{CH})$ : WHO Regional Office for Europe.

WHO (2015). International Statistical Classification of Diseases and Related Health Problems: 10th Revision. 5th Edn. Geneva $(\mathrm{CH})$ : World Health Organization.

Wundsam, K., Pitschel-Walz, G., Leucht, S., and Kissling, W. (2007). Psychiatric patients and relatives instruct German police officers. Psychiatr. Prax. 34 181-187. doi: 10.1055/s-2006-940065

Conflict of Interest: The authors declare that the research was conducted in the absence of any commercial or financial relationships that could be construed as a potential conflict of interest.

Publisher's Note: All claims expressed in this article are solely those of the authors and do not necessarily represent those of their affiliated organizations, or those of the publisher, the editors and the reviewers. Any product that may be evaluated in this article, or claim that may be made by its manufacturer, is not guaranteed or endorsed by the publisher. 
Copyright (c) 2021 Wittmann, Groen, Hampel, Petersen and Jörns-Presentati. This is an open-access article distributed under the terms of the Creative Commons Attribution License (CC BY). The use, distribution or reproduction in other forums is permitted, provided the original author(s) and the copyright owner(s) are credited and that the original publication in this journal is cited, in accordance with accepted academic practice. No use, distribution or reproduction is permitted which does not comply with these terms. 